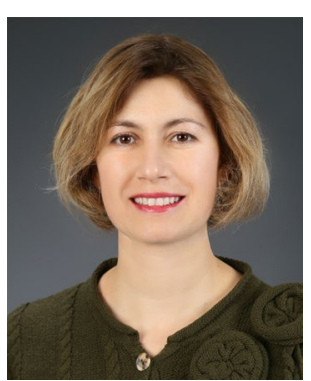

Credit: Deniz Çă̆daș

\title{
Living the SARS-CoV-2 pandemic in Turkey
}

To cope with the new situation during the pandemic, the Turkish people have united in the fight against SARS-CoV-2 with their healthcare workers, scientists and government. We are waiting for the global pandemic to end soon.

$\mathrm{T}$ he severe acute respiratory syndromecausing coronavirus (SARS-CoV-2) pandemic has profoundly influenced every area of social life, including health, education, technology and economics all over the world.

Turkey is a country acting as a bridge between Asia and Europe. The Turkish Ministry of Health (TMH) reported the first case of coronavirus disease 2019 (COVID-19) in Turkey on 11 March 2020. At the beginning of the pandemic, the TMH established the 'Coronavirus Scientific Advisory Board' to guide the pandemic regulations, and this board immediately prepared 'The SARSCoV-2 Risk Assessment and Guidelines' and 'The Guidelines for Convalescent Plasma Supply and Application' and regularly updated these according to the current scientific data. Mustafa Kemal Atatürk founded Turkey as a country that provides its people equal access to healthcare services. Thus, every patient has the chance to receive standard therapy free of charge, including antiviral drugs. TMH formed contact tracing (filiation) teams and charged the family physicians and officials to make house calls or visits twice a week to monitor the therapeutic compliance and disease progress of patients with COVID-19.

Inflammation, thrombosis and secondary infections seem to be the complicating factors in COVID-19. A growing body of data is pointing to the cardiac effects of the virus. Moreover, scientists have defined genetic susceptibility to SARS-CoV-2 (Zhang, Q. et al. Science 370, eabd4570, 2020) and showed the presence of autoantibodies against type I interferons (Bastard, P. et al. Science 370, eabd4585, 2020) in some patients with severe COVID-19. The disease is a public health problem. The mortality of the disease has been high, especially in older patients with chronic diseases. As of December 2020, about two million COVID-19 cases and 18,000 deaths have been reported in Turkey.

Worries about the risk of COVID-19 disrupted the public health programs like health follow-ups and visits to monitor children's health. The healthcare visit frequency has decreased by $60 \%$ during the pandemic (Ayhan Başer, D., Çevik, M., Gümüştakim, Ş. \& Başara, E. Int. J. Clin. Pract. 74, e13622, 2020). As a result, patients with chronic diseases have had greater problems with their primary disease and its complications than with COVID-19. The government has increased the capacity of healthcare centers, including intensive-care facilities. However, some patients still have concerns about the risk of not being hospitalized due to the increased demand.

Similar to other countries, the pandemic has seriously affected healthcare professionals and workers in Turkey. The filiation measures have become a part of their daily life. Many professors, doctors, and healthcare workers have died from the disease. Over 40,000 healthcare workers have tested positive for SARS-CoV-2, and over 200 of them have died of COVID-19 in a nine-month period in Turkey.

Throughout the pandemic, access to education has extensively varied. The shift to online education has been rapid because of the technological achievements of the last two decades. Nevertheless, it may be a challenge for rural families to get the tools and equipment needed for online education, and they would prefer their children to be working. Some people could conduct their work online, but many have given up their jobs to take care of their children at home. The short-term and long-term effects on the economy due to the pandemic have led to an increase in the unemployment rate, although public authorities like the local government and non-government organizations have provided support.

Education at home has been easier for children and the young, as the time loss due to transportation and the associated costs have decreased. But there are challenges regarding practical work, as some postgraduates would prefer to continue their education after the pandemic is over. Accordingly, there has been a relative labor loss in science and technology. Non-SARS-CoV-2 researchers are more affected than those researching SARS-CoV-2, as they have a lower probability of being funded.
Some industrial companies have altered their work to meet the demands of the pandemic, such as by manufacturing mechanical ventilators, masks, gloves and disinfectant liquids. Likewise, the number of medical studies and publications related to COVID-19 has increased, as there is a need for new scientific data to manage the disease better. 'The Scientific and Technological Research Council' has funded vaccine studies and the Turkish Ministry of Industry and Technology announced different vaccine projects under the COVID-19 platform.

While studies are still ongoing in Turkey and the world, public thoughts and attitudes concerning vaccines will be critical in disease management. A recent study reported that $35.9 \%$ of people did not decide whether they and their children would have a vaccine due to the fear and anxiety about the safety of the new vaccines and their possible adverse effects (Akarsu, B. et al. Int. J. Clin. Pract. https://doi. org/10.1111/ijcp.13891, 2020). The countries that manage to control the virus earlier will have an advantage regarding economic and political opportunities in the post-pandemic era (Açikgöz, Ö. \& Günay, A. Turk. J. Med. Sci. 50, 520-526, 2020). Living with a pandemic for nearly a year has substantially changed people's behavior and lifestyle. Life following the SARS-CoV-2 pandemic will not be the same. Now we need to move on and get back to a more normal life. I hope, as we have seen with science, each occupational area will find its way and that one positive consequence for the world may be the renewal of nature, at least partially.

\section{Deniz Çağdaș (D)}

Section of Pediatric Immunology, Department of Pediatrics, Institute of Child Health, İhsan Doğramacı Children's Hospital, Hacettepe University Medical School, Ankara, Turkey.

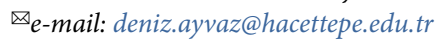

Published online: 24 February 2021 https://doi.org/10.1038/s41590-021-00887-4

Competing interests

The author declares no competing interests. 